\title{
A PRIORIDADE ONTOLÓGICA DOS CONTEÚDOS ESCOLARES
}

\author{
LA PRIORIDAD ONTOLÓGICA DE LOS CONTENIDOS ESCOLARES
}

THE ONTOLOGICAL PRIORITY OF SCHOOL CONTENTS

\author{
Rafael ROSSI ${ }^{1}$ \\ Aline Cristina Santana ROSSI ${ }^{2}$
}

\begin{abstract}
RESUMO: Com o presente texto problematizamos a relação entre conteúdos escolares e formas de ensino, sem supervalorizar unilateralmente um em detrimento do outro. Para tanto, partimos da abordagem histórica e ontológica para entender o processo de desenvolvimento e de formação humana, com objetivo de apreender a especificidade da educação. A partir destes entendimentos, consideramos que, de um ponto de vista preocupado com as autênticas necessidades humano-genéricas, os conteúdos escolares possuem a prioridade ontológica na prática educativa e se relacionam dialeticamente com as formas de ensino. Isto significa que a educação escolar deve estar comprometida com a promoção crítica, científica, artística e filosófica dos alunos, para além da imediaticidade do cotidiano em que se encontram.
\end{abstract}

PALAVRAS-CHAVE: Conteúdos escolares. Formas de ensino. Educação escolar. Professor.

RESUMEN: Con el presente texto problematizamos la relación entre contenidos escolares y formas de enseñanza, sin sobrevalorar unilateralmente uno en detrimento del otro. Para ello, partimos del enfoque histórico y ontológico para entender el proceso de desarrollo y de formación humana, con el objetivo de aprehender la especificidad de la educación. A partir de estos entendimientos, consideramos que, desde un punto de vista preocupado por las auténticas necesidades humano-genéricas, los contenidos escolares poseen la prioridad ontológica en la práctica educativa y se relacionan dialécticamente con las formas de enseñanza. Esto significa que la educación escolar debe estar comprometida con la promoción crítica, científica, artística y filosófica de los alumnos, además de la inmediatez de lo cotidiano en que se encuentran.

PALABRAS CLAVE: Contenidos escolares. Formas de enseñanza. Educación escolar. Maestro.

ABSTRACT: With the present text we problematize the relation between school contents and forms of teaching, without overvaluing unilaterally one to the detriment of the other. To do so, we start from the historical and ontological approach to understand the process of human

\footnotetext{
${ }^{1}$ Universidade Federal de Mato Grosso do Sul (UFMS), Campo Grande - MS - Brasil. Docente e Pesquisador na Faculdade de Educação e no Programa de Pós-Graduação em Educação. Pós-Doutorado em Educação (UNESP). ORCID: https://orcid.org/0000-0001-8544-3756. E-mail: rafaelrossied@gmail.com

${ }^{2}$ Universidade Federal de Mato Grosso do Sul (UFMS), Campo Grande - MS - Brasil. Pós-graduanda no Programa de Pós-Graduação em Ensino de Ciências. ORCID: https://orcid.org/0000-0002-8460-317X. E-mail: alinesantanarossi@gmail.com
} 
development and formation, in order to grasp the specificity of education. Based on these understandings, we consider that, from a point of view concerned with authentic humangeneric needs, school contents have the ontological priority in educational practice and are related dialectically to the forms of teaching. This means that the school education must be committed to the critical, scientific, artistic and philosophical promotion of the students, beyond the immediacy of the daily life in which they are.

KEYWORDS: School contents. Forms of teaching. Schooling. Teacher.

\section{Introdução}

No debate educacional, em geral, a reflexão sobre os conteúdos escolares e as formas de ensino aparece de modo desproporcional na maioria das análises. Ora, tende-se a priorizar os conteúdos em detrimento das formas, ora, em outros casos, inflaciona-se desmedidamente as formas de ensino secundarizando acriticamente os conteúdos escolares a serem transmitidos.

A tese que defendemos neste texto é a de que, nesta dinâmica inerente ao processo educativo, a prioridade ontológica cabe aos conteúdos escolares que, por sua vez, se relacionam dialeticamente com as formas de ensino. Nossa fundamentação teórica se dá a partir das contribuições de Lukács (2012; 2013) e Duarte (2016), bem como de outros autores na mesma abordagem da perspectiva crítica ontológica.

Desse modo, para provarmos nossa tese, em primeiro lugar, apresentamos os fundamentos onto-metodológicos da reflexão que estrutura o presente texto. O prefixo "onto" é necessário, pois entendemos que a realidade objetiva existe, com suas legalidades próprias, independente de nossos anseios, vontades, sonhos ou desejos. A realidade existe independentemente da consciência. Além disso, não são apenas aspectos metodológicos, mas antes disso, são aspectos onto-metodológicos, ou seja, tratam-se de parâmetros intelectivos extraídos a partir do próprio exame do movimento essencial da totalidade do real. Não se trata, portanto, de princípios construídos pela subjetividade que reflete a si mesma, mas da consciência que se esforça por traduzir a lógica do real, para além de suas aparências.

A partir destas compreensões poderemos avançar para, posteriormente, a relação efetiva entre conteúdos escolares e formas de ensino, numa prerrogativa preocupada com as autênticas necessidades humanas em seu processo formativo e de desenvolvimento e não com as demandas alienadas e alienantes dos imperativos do mercado.

Por fim, nossas considerações finais a respeito deste importante debate no âmbito da educação escolar e da formação de professores. 


\section{Fundamentos onto-metodológicos}

Para iniciar este debate é preciso explicitar nossa compreensão de formação e desenvolvimento humano, pois é a partir disso que a problemática da especificidade da educação poderá se evidenciar de modo mais claro e preciso. Nesse aspecto, a partir dos subsídios de Lukács (2013), entendemos que a humanidade surge a partir de um salto de qualidade, um salto estrutural, ou seja, um salto ontológico do ser orgânico ao ser social, proporcionado pelo trabalho em articulação com as relações sociais, a cooperação e a comunicação.

O trabalho é entendido enquanto interação da sociedade com a natureza para a produção das condições materiais da existência social. Para que a vida em sociedade possa se concretizar, é preciso a transformação intencional e consciente da realidade natural. Este processo marca a dinâmica do trabalho. Lukács (2013), afirma que com o trabalho surge um efetivo pôr teleológico. Isto significa que a consciência humana analisa os elementos presentes na natureza, pensa as possibilidades concretas, os vínculos e articulações que podem ser estabelecidos e, a partir da atuação real, os seres humanos objetivam, isto é, criam, algo eminentemente novo, algo oriundo apenas da ação humana. Um machado, por exemplo, não se origina do auto movimento das pedras e da madeira. Ele possui esses elementos naturais em sua constituição, porém, sua existência se deve aos atos de trabalho humanos teleologicamente orientados.

Com isso, geram-se conhecimentos, habilidades e valores que irão se generalizar e poderão ser utilizados em outras situações distintas. Os seres humanos transformaram a natureza de modo conscientemente intencional para atender uma necessidade social (se alimentar, se proteger, etc.) e, ao mesmo tempo, transformaram as suas próprias individualidades. O ser humano que trabalha, com o processo de objetivação, pode aprender com a sua atividade, se enriquecendo culturalmente e ampliando o horizonte de compreensão e de possível intervenção na objetividade. O processo de reprodução social, ainda de acordo com Lukács (2013), é um processo em que há a incessante produção do novo: novas habilidades, novas necessidades, novas possibilidades de transformação da realidade, novos complexos sociais (educação, ciência, arte, filosofia), novas objetivações e novas apropriações.

Teremos, deste modo, sociedades e individualidades mais complexas. Haverá novos complexos sociais interagindo junto ao trabalho e conformando uma totalidade social. A totalidade, neste aspecto, é sempre a síntese qualitativa das várias interações que as dimensões 
sociais estabelecem entre si. Toda totalidade social é oriunda de um processo histórico e apresenta as possibilidades e os obstáculos para a atuação de cada dimensão social.

Temos com isso uma primeira constatação onto-metodológica: a realidade existe independentemente da consciência. Segunda constatação: a consciência que se propõe intervir na realidade precisa se empenhar em conhecer a realidade como ela é em si mesma, para além das aparências, no que concerne à sua dinâmica essencial. Terceira constatação: com a objetivação (material e intelectual) os seres humanos ampliam as possibilidades de complexificação e desenvolvimento das sociedades e de suas próprias individualidades. Quarta constatação: compreender algum fenômeno exige a investigação sobre seu processo de constituição e sua natureza mais íntima, bem como a sua articulação com a totalidade com a qual interage. Abandonar a totalidade é abandonar a possibilidade de um entendimento racional e respaldado na objetividade.

A especificidade da educação, em seu sentido amplo, está nos conhecimentos que foram criados com os atos de trabalho. Para que as novas gerações possam se desenvolver e continuar com os processos de reprodução social, é preciso que se apropriem das objetivações materiais e espirituais que foram elaboradas historicamente pelas gerações passadas. Esse processo de transmissão e apropriação de conhecimentos marca a natureza da educação.

Todavia, nem a educação, nem qualquer outro complexo social, se desenvolvem e atuam de qualquer maneira aleatória. Eles atuam numa totalidade social historicamente determinada. É sempre a totalidade que irá colocar as possibilidades e os entraves/obstáculos para a educação atuar. No caso da sociedade capitalista na qual vivemos, temos o potencial de todos os seres humanos se desenvolverem plenamente em todos os aspectos (artísticos, científicos, culturais, filosóficos, etc.). Contudo, este potencial (que foi construído graças aos avanços alcançados pelas forças produtivas neste modo de produção) não se concretiza de modo absoluto em razão do modo como as relações sociais de produção se estruturam no capitalismo. Nesta sociedade, o trabalho é explorado e a produção social em seu sentido amplo (desde a produção das mercadorias, até a produção das ideologias, conhecimentos etc.) é orientada para atender as demandas do mercado, para atender os imperativos da reprodução do capital e dos lucros. Sem o entendimento de como funciona a sociedade, tenderemos a exigir da realidade possibilidades que ela não oferece concretamente e, com isso, cairemos no idealismo, ou seja, na deturpação, consciente ou não, da objetividade a partir do que deseja e do que cria a subjetividade.

Temos aqui a prioridade ontológica da objetividade, com a "constatação de que o ente originário é sempre uma totalidade dinâmica, uma unidade de complexidade e 
processualidade" (LUKÁCS, 2012, p. 304). Isto significa que na análise da educação é preciso compreendê-la em seu relacionamento com o todo existente na realidade objetiva. Com efeito, quando "atribuímos uma prioridade ontológica a determinada categoria com relação a outra, entendemos simplesmente o seguinte: a primeira pode existir sem a segunda, enquanto o inverso é ontologicamente impossível", ou seja, "pode haver ser sem consciência, enquanto toda consciência deve ter como pressuposto, como fundamento, algum ente" (LUKÁCS, 2012, p. 307).

Do ponto de vista da pesquisa em educação e da atuação do professor na educação escolar, podemos refletir a partir das elaborações de Lukács que: 1) a educação em suas articulações com a totalidade existe independente das pesquisas e; 2) a atuação do professor deve ser no reconhecimento da essência da realidade para apreender a relação entre conteúdo escolar e formas de ensino.

A educação escolar, no capitalismo, sofre uma contradição aguda que é expressão do movimento da própria sociedade em sua dinâmica exploratória. Por um lado, as escolas sofrem interferência dos interesses das classes dominantes e, com isso, de certo modo, ajudam na disseminação de valores que defendam esta sociedade, ocultando e deturpando seu modo de funcionamento, para que os alunos possam ser formados para a aceitação e a conformação com a vida nas atuais relações sociais de produção. Não por um acaso, o empreendedorismo, na atualidade, esteja com muita força nas universidades e nas escolas. Por outro lado, é na escola que os filhos dos trabalhadores terão mínimas chances de se apropriarem dos rudimentos das ciências naturais e sociais, dos conhecimentos matemáticos, físicos, químicos, geográficos, históricos, etc.

Por isso, de um ponto de vista preocupado com as autênticas necessidades humanogenéricas, é imprescindível que os professores atuem na educação escolar no sentido de contribuir com o desenvolvimento e a elevação do nível cultural, fillosófico, artístico e intelectual dos alunos. Uma escola que apenas contribui para a reprodução do senso comum e para a apreensão epidérmica da realidade é uma escola que, consciente ou não, auxilia enormemente os interesses das classes dominantes na manutenção desta sociedade. A reflexão sólida sobre conteúdos e formas, no processo educativo, é de extrema importância no debate da educação escolar e na formação de professores. Vejamos mais a este respeito, a partir das constatações e dos parâmetros onto-metodológicos que abordamos anteriormente. 


\section{Conteúdos e formas: para além da primazia unilateral}

O próprio título desta divisão do texto é provocativo ao afirmar "para além da primazia unilateral". Isto significa que, de modo geral, tende-se a valorizar as formas de ensino, como presente nas pedagogias baseadas no construtivismo e, portanto, as pedagogias do "aprender a aprender", que afirmam que aquilo que os alunos aprendem sozinhos é mais importante do que aquilo que poderiam aprender com a mediação dos outros, com a mediação dos professores e; ainda, que o processo de construção do conhecimento e os seus métodos de aquisição seriam mais importantes do que os conhecimentos que, de fato, fossem transmitidos pela educação (DUARTE, 2011).

Por outro lado, em alguns casos, costuma-se valorizar demais os conteúdos sem a reflexão necessária das formas, como por exemplo ocorreu com a Pedagogia Tradicional. Tanto em uma como em outra perspectiva não há uma compreensão dialética, ou seja, um entendimento das interações e do momento predominante que um pode estabelecer sobre o outro. A este respeito:

[...] nenhuma interação real (nenhuma real determinação de reflexão) existe sem momento predominante. Quando essa relação fundamental não é levada na devida conta, tem-se ou uma série causal unilateral e, por isso, mecanicista, simplificadora e deformadora dos fenômenos, ou então aquela interação carente de direção, superficialmente rutilante, cuja ausência de ideia Hegel criticou com razão em seu tempo, mas sem encontrar solução para o problema (LUKÁCS, 2012, p. 333-334, grifo nosso).

A categoria de "momento predominante" significa que em uma determinada relação social e, portanto, existente na objetividade, um dos momentos irá colocar os rumos, as possibilidades, os fundamentos e os entraves para as outras atuarem. Por exemplo: o trabalho é o momento predominante no surgimento da humanidade, pois como demonstramos anteriormente, ele possibilitou uma articulação nova entre consciência e objetividade que, por sua vez, fundou novas necessidades sociais e novos complexos com funções distintas na reprodução das sociedades. Com relação a cada um dos complexos sociais, como a educação em nosso caso aqui em debate, é sempre a totalidade social que exerce o papel de momento predominante. Esta categoria de momento predominante permite-nos evitar tanto o idealismo na educação que acredita que ela possui uma autonomia absoluta frente à sociedade e, ao mesmo tempo, o imobilismo derrotista que entende que ela nada pode contribuir de modo positivo. 
Estes entendimentos são fundamentais para atingir um determinado objetivo e uma possível intervenção na realidade de modo eficaz. No caso da educação escolar, a atuação dos professores deve ser uma atuação teleologicamente orientada, ou seja, deve ter como preocupação primeira a orientação geral do seu ensino: numa perspectiva espontaneísta que não possibilite aos alunos irem além da imediaticidade fenomênica do real, ou, por outro lado, no sentido da promoção e do desenvolvimento humano-genérico?

Se o objetivo for contribuir com a promoção crítica e cultural dos alunos, então, nesse caso, a relação entre conteúdos escolares e formas de ensino não pode ser secundarizada ou abandonada. O momento predominante que a totalidade social capitalista nos coloca permite entender que a plena socialização dos conhecimentos elaborados e sistematizados (das ciências, das artes e da filosofia) é algo impossível em ser realizado de modo absoluto, perante todas as escolas, todos os professores e todos os alunos. A reprodução da lógica de exploração e dos imperativos dos lucros impede que isso se realize em toda sociedade. Contudo, algumas ações educativas humanamente emancipatórias são possíveis nesta direção.

Nesse aspecto, entendemos que os conteúdos escolares possuem a prioridade ontológica na relação com as formas de ensino. Isto quer dizer que é a partir da seleção dos conteúdos a serem transmitidos (com o objetivo de contribuir com o desenvolvimento humano e crítico dos alunos) que podemos pensar as formas do seu ensino. Se invertermos esta relação e pensarmos as formas em primeiro lugar e os conteúdos de modo secundarizado, então estaremos agindo no sentido das pedagogias do "aprender a aprender", para as quais a "aprendizagem significativa" é aquela que coaduna com os interesses imediatos (e não os essenciais) dos alunos.

Se o objetivo é auxiliar os alunos a avançarem suas análises e suas percepções de mundo e de sociedade para além das aparências, então, os conteúdos escolares jogam um papel decisivo. Não se trata de transmitir qualquer conteúdo. É imprescindível que se mobilizem esforços no sentido da transmissão e da assimilação dos conhecimentos elaborados historicamente no campo das ciências, das artes e da filosofia. Saviani (2008) sintetiza de modo preciso esta importância:

Os conteúdos são fundamentais e sem conteúdos relevantes, conteúdos significativos, a aprendizagem deixa de existir, ela transforma-se num arremedo, ela transforma-se numa farsa. Parece-me, pois, fundamental que se entenda isso e que, no interior da escola, nós atuemos segundo essa máxima: a prioridade dos conteúdos, que é a única forma de lutar contra a farsa do ensino. Por que esses conteúdos são prioritários? Justamente porque o domínio da cultura constitui instrumento indispensável para a participação política das massas. Se os membros das camadas 
populares não dominam os conteúdos culturais, eles não podem fazer valer os seus interesses, porque ficam desarmados contra os dominadores, que se servem exatamente desses conteúdos culturais para legitimar e consolidar a sua dominação. Eu costumo, às vezes, enunciar isso da seguinte forma: o dominado não se liberta se ele não vier a dominar aquilo que os dominantes dominam. Então, dominar o que os dominantes dominam é condição de libertação (SAVIANI, 2008, p. 45, grifo nosso).

Tais conhecimentos clássicos guardam importantes elaborações a respeito da realidade em sua essência e, por meio da crítica, ou seja, do seu confronto com a objetividade ao longo do tempo, o professor pode auxiliar os alunos no sentido de seu desenvolvimento humanogenérico. Este entendimento é lucidamente abordado por Duarte (2016) ao afirmar que:

[...] os conhecimentos científicos, artísticos e filosóficos carregam atividade humana condensada, sintetizada, ou seja, vida em forma latente. O trabalho realizado sobre esses conhecimentos, com a finalidade de transmiti-los às novas gerações, traz os mortos novamente à vida. Mas esse milagre da ressurreição, realizado pela atividade educativa, tem como consequência que os mortos ressurretos apoderem-se dos vivos, ou seja, a atividade contida nesses conhecimentos transforma-se em atividade mental dos alunos e se incorpora à sua individualidade [...] (DUARTE, 2016, p. 02, grifo nosso).

Vejamos, de modo mais detalhado, cada uma das contribuições que estes conhecimentos podem fornecer. Comecemos pela ciência. Lukács nos ensina que:

Na medida em que as experiências de um trabalho concreto são utilizadas em outro, ocorre gradativamente sua - relativa - autonomia, ou seja, a fixação generalizadora de determinadas observações que já não se referem de modo exclusivo e direto a um único procedimento, mas, ao contrário, adquirem certa generalização como observações de eventos da natureza em geral. São essas generalizações que formam os germes das futuras ciências (LUKÁCS, 2013, p. 86).

Ou seja: à ciência cabe o conhecimento objetivo, o conhecimento da essência da realidade ao longo do processo histórico. Hoje, o momento em que a sociedade capitalista atravessa, contribuir com a produção e a transmissão da ciência que trate de desvendar a essência dos objetos e dos fenômenos que estuda é uma preocupação conectada com os interesses da classe trabalhadora, pois, como já afirmamos, as classes dominantes apenas possuem o interesse na manutenção e na perpetuação do capitalismo, mesmo que isto custe a vida de milhões de pessoas que morrem de fome, nas guerras, com os conflitos agrários, etc. Com relação à arte:

[...] no centro da arte se encontra o homem como ele se configura em individualidade genérica nos conflitos com o seu mundo e o seu meio ambiente [...] a antropomorfização da esfera estética constitua um pôr 
consciente, em contraposição à antropomorfização espontânea da vida cotidiana [...] (LUKÁCS, 2013, p. 543).

A arte, assim como a ciência, fornece um tipo de conhecimento. Todavia, não é um tipo de conhecimento que, como a ciência, precisa ser objetivo e, para isso, não pode deixar a consciência atrapalhar nesse processo. A arte é antropomorfizadora, isto é, ela conecta os indivíduos com o gênero humano, fornecendo um quadro da totalidade social de referência analisada, na qual é possível apreender a trajetória da humanidade em seus conflitos e suas potencialidades. A arte trabalha diretamente com a subjetividade, no sentido de nos enxergarmos enquanto membros do gênero. A filosofia, por sua vez:

O objeto central da filosofia é o gênero humano, isto é, uma imagem ontológica do universo e, dentro desta, da sociedade a partir do aspecto de como ela realmente foi, veio a ser e é para que produzisse como necessário e possível cada um dos tipos atuais de generidade; ela une, portanto, sinteticamente os dois polos: mundo e homem na imagem da generidade concreta (LUKÁCS, 2013, p. 543).

A autêntica filosofia, para Lukács, problematiza as grandes questões do gênero humano em seu movimento histórico de constituição do presente e de possibilidade para o futuro. A filosofia, portanto, não serve como manipulação, mas esclarecimento. De modo extremamente rápido, tanto as ciências, quanto as artes e a filosofia, fornecem formas de conhecimento que contribuem de modo extremamente positivo na formação intelectual e cultural de alunos e professores. Contudo, é preciso que o esforço de apropriação e de transmissão da crítica ontológica sobre estes conhecimentos também se faça presente, pois ela se refere à uma crítica concreta, "fundada na respectiva totalidade social e orientada para a totalidade social" (LUKÁCS, 2013, p. 97-98). Desse modo:

A arte apropria-se desse fenômeno que existe na vida e o transforma em um efeito produzido sobre os indivíduos pela obra artística. No caso das obras científicas e filosóficas, a catarse ocorre de maneiras não idênticas à catarse estética, o que se explica pelo simples fato de que arte, ciência e filosofia são tipos distintos de apropriação da realidade pela consciência. Mas as obras desses três campos mais elevados de produção humana podem, pela mediação do trabalho educativo, produzir saltos qualitativos decisivos em termos de desenvolvimento da visão de mundo dos indivíduos. Assim como no caso das obras artísticas, também os conhecimentos científicos e filosóficos podem gerar mudanças importantes na visão de mundo dos indivíduos (DUARTE, 2016, p. 18, grifo nosso).

Podemos perceber claramente, que do ponto de vista preocupado com o desenvolvimento intelectual dos alunos, não é qualquer conteúdo que deve ser transmitido pela educação escolar. Por outro lado: aquilo que se restringe ao senso comum, aquilo que é 
vulgar, aquilo que deturpa o ser humano em essências concebidas de modo idealista e preconceituoso, aquilo que desvaloriza os conhecimentos elaborados e sistematizados pelo gênero; tudo isso deve ser repudiado. As formas mais elaboradas dos saberes científicos, estéticos e filosóficos, por meio de uma abordagem crítica, fornecem subsídios fundamentais para que os alunos reflitam as suas vidas, as contradições sociais, as grandes questões que afligem hoje a humanidade e se posicionem de modo consciente e organizado na prática social. Importante lembrar que:

Não adianta nada eu ficar sempre repetindo o refrão de que a sociedade é dividida em duas classes fundamentais, burguesia e proletariado, que a burguesia explora o proletariado e que quem é proletário está sendo explorado, se o que está sendo explorado não assimila os instrumentos pelos quais ele possa se organizar para se libertar dessa exploração. Associada a essa prioridade de conteúdo, que eu já antecipei, parece-me fundamental que se esteja atento para a importância da disciplina, quer dizer, sem disciplina esses conteúdos relevantes não são assimilados (SAVIANI, 2008, p. 45).

Concordamos com o posicionamento de Saviani (2008). O comprometimento social e político do professor com seus alunos, filhos da classe trabalhadora, não ocorre por meio de politicismos ou panfletagens quaisquer. Ao contrário, o professor demonstra sua competência e seu compromisso quando transmite criticamente aquilo que de mais elaborado existe no campo das objetivações intelectuais, científicas e estéticas aos seus alunos, trabalhando com o rigor e a historicidade necessária à sua própria disciplina.

As formas de ensino, nesse sentido, devem se subordinar aos conteúdos escolares estruturados a partir dos clássicos do conhecimento sistematizado. Além disso, as próprias formas de ensino contribuem, a partir da prioridade ontológica dos conteúdos, a serem repensadas. Se a preocupação é com a transmissão dos clássicos, numa orientação crítica, as formas de ensino, a partir da atuação dos professores, podem ser alteradas, sem prejudicar os conteúdos. As formas podem variar de turma para turma, de série escolar para série, em função da faixa etária dos alunos, etc. Contudo, o que não pode ser vulgarizado são os conteúdos a serem ensinados. A importância dos clássicos nos conteúdos escolares pode ser entendida a partir desta constatação:

Se o conhecimento não transformasse as pessoas e não transformasse a sociedade, ele não passaria de uma massa morta de informações, palavras e ideias. Mas o conhecimento é atividade humana condensada e sua socialização traz à vida a atividade que ali se encontra em estado latente. Essa atividade, no processo de sua apropriação pelos indivíduos, produz nestes o movimento do intelecto, dos sentimentos e da corporeidade, em outras palavras, põe em movimento o humano (DUARTE, 2016, p. 34, grifo nosso). 
Os conhecimentos clássicos, portanto, contribuem positivamente na formação humana dos alunos e dos próprios professores. Aliás:

O clássico é, em si mesmo, uma unidade entre conteúdo e forma e, ao ser transformado em conteúdo escolar, pode ser trabalhado por meio de diferentes formas didáticas. Não existe "a" forma de ensinar da pedagogia histórico-crítica, posto que a decisão pelo emprego de uma estratégia, uma técnica ou um procedimento didático dependerá sempre de uma avaliação que relacione, no mínimo, quatro elementos: quem está ensinando, que está aprendendo, o que está sendo ensinado e em que circunstâncias a atividade educativa se realiza. Claro que nessa avaliação se coloca sempre como pressuposto, em se tratando dessa pedagogia, que há algo a ser ensinado e cabe ao professor a tarefa de efetivação do ato de ensinar. Por sua vez, esse pressuposto conecta-se a outro, o de que há conteúdos científicos, artísticos e filosóficos que se constituem em valores conquistados pelo desenvolvimento histórico do gênero humano e são representativos [...] (DUARTE, 2016, p. 109, grifo nosso).

Enfim, conteúdos escolares e formas de ensino se relacionam dialeticamente. Todavia, do ponto de vista dos interesses autênticos do gênero humano, a prioridade ontológica cabe aos conteúdos e não às formas, pois são os clássicos das artes, das ciências e da filosofia que poderão desenvolver intelectual e criticamente nossas concepções de mundo. Não é por um acaso qualquer que a sociedade capitalista coloque a prioridade ontológica justamente nas formas, pois neste caso, o debate educacional praticamente esquece a importância dos conteúdos e os adjetiva de modo pejorativo, auxiliando ainda mais a confusão no entendimento desta ordem societária perante os próprios trabalhadores. Colocar a prioridade ontológica nas formas de ensino e não sobre os conteúdos é, portanto, contribuir com a produção social das ilusões pedagógicas que nos aliena do entendimento verdadeiro e racional da vida nesta forma de sociabilidade.

\section{Considerações finais}

Neste texto abordamos importante temática na educação escolar e na formação de professores que é a relação entre conteúdos escolares e formas de ensino. Para tanto, partimos do processo de desenvolvimento e formação humana a partir de bases históricas e ontológicas. Demonstramos, a partir das elaborações de Lukács (2012; 2013), que o trabalho permitiu o salto ontológico do ser orgânico ao ser social, pois apresentou um efetivo pôr teleológico, ou seja, uma articulação entre consciência e realidade. Nesse sentido, a realidade objetiva existe independentemente da consciência. Caso a consciência queira intervir na transformação da 
realidade para atingir um determinado objetivo social e histórico, então, é preciso compreender a objetividade em seu próprio movimento essencial e total.

Explicitamos que a totalidade social é sempre o momento predominante na orientação dos complexos sociais, pois é ela quem coloca as oportunidades, entraves, possibilidades e obstáculos existentes. Dessa forma, explicar de modo racional é levar em consideração as múltiplas articulações e determinações do objeto em questão com a totalidade. Os seres humanos para se desenvolverem precisam se apropriar das objetivações materiais e espirituais construídas pelas gerações passadas. O nível desta apropriação e quais objetivações serão transmitidas e apropriadas são questões que poderemos responder ao analisarmos a respectiva totalidade social em enfoque.

A educação escolar, no capitalismo, assim como os demais complexos da vida em sociedade, atravessa uma enorme contradição. Por um lado, ela é utilizada pelas classes dominantes no sentido de confundir e inculcar a aceitação e o conformismo entre os trabalhadores. Por outro lado, do ponto de vista humano-genérico e não do ponto de vista dos interesses do mercado, a escola é uma instituição que pode contribuir com a transmissão dos conteúdos clássicos das ciências, das artes e da filosofia. O objetivo, nesta última perspectiva traçada, é o desenvolvimento intelectual e crítico dos alunos e professores.

Com efeito, também aqui Lukács (2013) muito pode nos esclarecer ao explicar que à ciência cabe a função social de explicitar e traduzir o movimento, a essência, as articulações com a totalidade do respectivo objeto em análise. A grande arte tem a função social de conectar os indivíduos com o gênero humano de modo culturalmente enriquecedor e humanamente emancipatório. Já a autêntica filosofia, por sua vez, contribui os indivíduos a refletirem a trajetória do gênero em suas continuidades e rupturas, bem como as grandes e essenciais questões que a totalidade social hoje nos coloca.

Portanto, se o objetivo é a elevação cultural e crítica dos alunos, os conteúdos escolares possuem a prioridade ontológica e se relacionam dialeticamente com as formas de ensino. Estas, podem ser refletidas à luz das especificidades de cada contexto. O que não pode variar é a preocupação com a transmissão dos clássicos, por meio dos conteúdos escolares. Isto, vale a pena enfatizar mais uma vez, se tivermos como norte geral a promoção uma prática educativa humanamente emancipatória. Vale a pena lembrar sempre que a arte, as ciências e a filosofia, por meio da crítica ontológica, sintetizam "a experiência históricocultural, constituindo-se em mediações que aumentam as possibilidades de domínio, pelos seres humanos, das circunstâncias externas e internas a partir das quais eles fazem sua história” (DUARTE, 2016, p. 44). 


\section{REFERÊNCIAS}

DUARTE, N. Vigotski e o "aprender a aprender": crítica às apropriações neoliberais e pósmodernas da teoria vigotskiana. 5. ed. Campinas, SP: Autores Associados, 2011.

DUARTE, N. Os Conteúdos escolares e a ressurreição dos mortos: contribuição à teoria histórico-crítica do currículo. Campinas, SP: Autores Associados, 2016.

LUKÁCS, G. Para uma ontologia do ser social - I. São Paulo: Boitempo: 2012.

LUKÁCS, G. Para uma ontologia do ser social - II. São Paulo: Boitempo: 2013.

SAVIANI, D. Escola e democracia. Campinas, SP: Autores Associados, 2008.

\section{Como referenciar este artigo}

ROSSI, R.; ROSSI, A. C. S. A prioridade ontológica dos conteúdos escolares. Revista IberoAmericana de Estudos em Educação, Araraquara, v. 15, n. 4, p. 1954-1966, out./dez. 2020. e-ISSN: 1982-5587. DOI: https://doi.org/10.21723/riaee.v15i4.12604

Submetido em: 01/06/2019

Revisões requeridas em: 20/11/2019

Aprovado em: $24 / 02 / 2020$

Publicado em: $30 / 08 / 2020$ 